increases is influential in eliminating the inhibitory factor.

Rowand R. J. Chattee

Division of Life Sciences,

University of California, Riverside.

' Chaffee, R. R. J., thesis, Harvard University (1957).

'Chaffee, R. R. J., Hoch, F. L., and Lyman, C. P., Amer. J. Physiol., 201, 29 (1961).

'Lyman, C. P., and Chatfield, P. O,, Physiol. Rev., 35, 403 (1955).

'Hoch, F. L., and Lipmann, F., Proc. US. Nat. Acad. Sci., 40, 909 (1954)

'Lehninger, A. L,, Rev, Mod. Phys., 31, 136 (1959).

\section{Chromatophoric Responses of Eyestalk-less Shrimps}

Rrmoval of the eyestalk from a shrimp, Palaemon serratus, induces complete dispersal of the bichromatic chromatophores of tho body. Afterwards, the general coloration of the shrimp becomos red. The bands appear as marked and continuous lines. This coloured aspect is reached a fow hours after the bilateral removal and eyestalkless shrimps koop it permanently, in spite of the background colour.

In the experiments reported here, I noticed that the chromatophoric behaviour of eyestalkless shrimps did not settle completely after bilateral ablation.

Twelve Palaemon serratus, in the $C$-stage of their intermoult, were previously kept on white background under illumination for two weeks. Eyestalks were then cut off, on February 1, and the shrimps were set again on white background, in individual containers, supplied with running sea-water. Animals were fed twice a week. Water temperature was about $13^{\circ}$ to $16^{\circ}$ for two months (February and March). During this time, the shrimps moulted twice.

After removal of the eyestalks, they darkened quickly and remained red throughout February. Early in March, the colour became paler, by loss of pigmont and by concentration of chromatophores. These operated animals became as white as control animals, which were maintained on illuminated white background for the same time. The band chromatophores were dispersed at intermodiate stages, and those scattered on the body strongly concentrated. On March 19, six of these eyestalkless Palaemon were removed from their white background and put before a dark one. Six controls were treated the same. Chromatophores of the eyestalkless shrimps began then to expand for $24 \mathrm{~h}$, so that shrimps were finally pale rod, slightly pink. This colour was quito different from the white colour of the other blind shrimps left on the white background. The normal animals, placed on dark background, darkened too: their chromatophores were loss expanded than those of the operated shrimps, but their coloured aspect was undoubtedly more evident, because of the blue diffusion and of norrnal rate of pigmentation in cells. All these animals were once more set again on white background, after three days of black adaptation. Chromatophores of these six eyestalkless Palaemon did not soom to concentrate or became so sluggish that concentration was no longer apparent. Intact animals changed and became pale normally.

In this case, a darkening substance acts, which does not depend on the eyestalk. Knowles, Carlisle and Dupont-Raabe ${ }^{1}$ separated dispersing and concentrating substances from post-commissural organ extracts by olectrophoresis, and Brown, Wobb and Sandeen ${ }^{2}$ have pointed out that the highest ratio of red dispersing hormone to concentrating substance is found in the abdominal cord. But we may suppose, in this special assay of adaptation, existence of photoreceptors, different from eyes, or a direct and secondary action of light, either on chromatophores (Fingerman et al. ${ }^{3}$ gave examples of responses of melanophores of eyestalkless Sesarma reticulatum to incident light) or may be the abdominal nerve cord. On the other hand, these results must be compared with the experimental analysis of the responses of chromatophores of Palaemonetes vulgaris to long adaptation". This experience gave evidence of stocking of chromatophoric substances, which were not used for adaptation, in post-commissural organs. Here the previous white adaptation may have led to storage of darkening substanco. Finally, I must refor to the persistence of activators of pigment in supraøesophageal and circumphageal connectives, established by Fingerman and Mobberly ${ }^{5}$ in a cave-blind crayfish, Orconectes pellucidus australis. It demonstrated that "the loss of the controlling mechanism takes longer than the loss of the end organ". I found a similar situation here.

\section{Faculté des Sciencess,}

Chantal Pasteur-Humbert

Institut Scientifique Chérifien, Rabat, Morocco. 3 Knowles, F. G. W., Carlisle, D. B., and Dupont-Raabe, M., J. Mar.
Biol. Assoc., 34 , 611 (1955).

${ }^{2}$ Brown, jun., F. A., Webb, H. M., and Sandeen, M. I., J. Exp. Zool., Fingerman, M., Nagabhushanam, R., and Philpott, L., Biol. Butl.,
119, No. 2, 315 (1960); 120, No. 3, 337 (1961).

Fingerman, M., and Sandeen, M. I., Physiol. Zool., 22, No. 2, 128

- Fingerman, M., and Mobberly, jun., W. C., Science, 132, 44 (1960).

\section{Photophore and Eye Movement in the Euphausiid Meganyctiphanes norvegica} (G. O. Sars)

THE complex structure of the light-emitting organs of euphausiids has long been known ${ }^{1,2}$, though their precise function has eluded investigators. While examining further this problem, it has become clear that these organs, all of which are movable except those on the eye-stalks, do not operate independently but may be co-ordinated. Meganyctiphanes has 10 photophores, one incorporated in the eye-stalk below each eye, 4 in the thoracio region at the bases of the 2nd and 7th pairs of appendages, and one between each of the first 4 pairs of pleopods. The eye-stalks, bearing the large compound eyes and photophores, project laterally and aro closely approximated at their base in such a way that the eyes, though they may be moved independently to some extent, may be turned togother in the sagittal plane, tho amount of possible rotation boing greater than $90^{\circ}$. The thoracie and abdominal photophores can turn through nearly $180^{\circ}$ to face forwards, ventrally, or backwards.

Fresh specimens may be soon to flash brilliantly when handled in the dark ${ }^{3}$, and they may afterwards glow at a lower intensity for variable periods, with all the photophores in action. The stimuli inciting the different luminescent reactions are at present under investigation ${ }^{4}$.

The co-ordinated movement of the eyes and photophores may be seen by observing luminescing speci. mens retained ventral side uppermost in a dark room in red light. When making these observations the animals were held by threads on a 'Perspex' plate and were viewed with a binocular microscope or hand-lens. 